5 Heinrich $\mathrm{M}$, Uder $\mathrm{M}$, Tscholl $\mathrm{D}$, et al. CT scan findings in chronic thromboembolic pulmonary hypertension: predictors of hemodynamic improvement after pulmonary thromboendarterectomy. Chest 2005; 127: 1606-1613. Mayer E, Jenkins D, Lindner J, et al. Surgical management and outcome of patients with chronic thromboembolic pulmonary hypertension: results from an international prospective registry. J Thorac Cardiovasc Surg 2011; 141: 702-710.

7 Condliffe R, Kiely DG, Gibbs JS, et al. Prognostic and aetiological factors in chronic thromboembolic pulmonary hypertension. Eur Respir J 2009; 33: 332-338.

8 McLaughlin VV, Badesch DB, Delcroix M, et al. End points and clinical trial design in pulmonary arterial hypertension. J Am Coll Cardiol 2009; 54: Suppl. 1, S97-S107.

9 Ng CS, Wells AU, Padley SP. A CT sign of chronic pulmonary arterial hypertension: the ratio of main pulmonary artery to aortic diameter. $J$ Thorac Imaging 1999; 14: 270-278.

10 Haimovici JB, Trotman-Dickenson B, Halpern EF, et al. Relationship between pulmonary artery diameter at computed tomography and pulmonary artery pressures at right-sided heart catheterization. Massachusetts General Hospital Lung Transplantation Program. Acad Radiol 1997; 4: 327-334.

\title{
Plasma interleukin-6 adds prognostic information in pulmonary arterial hypertension
}

\author{
To the Editor:
}

Noninvasive biomarkers are needed to aid in making challenging clinical decisions in pulmonary arterial hypertension (PAH). Several biomarkers have been described, but only the natriuretic peptides have gained clinical utility. A key question to answer is whether or not a new biomarker adds independent incremental information [1]. Novel PAH markers may be discovered from new pathobiological pathways, such as inflammation. In particular, interleukin (IL)-6 has been linked with the development of severe pulmonary hypertension in animal models, mimicking the pathology of human disease [2]. IL-6 is a major regulator of the production of C-reactive protein (CRP), a marker of cardiovascular risk [3]. We conducted this study to determine if these inflammatory biomarkers add incremental prognostic information in PAH.

This is a cohort study based on a prospective Biobank. We enrolled patients with idiopathic, heritable, connective tissue-associated and congenital heart disease-associated PAH, as defined by current guidelines [4], between March 2005 and June 2011. The study was approved by the Cleveland Clinic Institutional Review Board. We used ELISA (R\&D Systems Inc., Minneapolis, MN, USA) to measure IL-6, the Abbott platform for highly-sensitive CRP (hsCRP) (Abbott Laboratories, Abbott Park, IL, USA) and a chemiluminescence immunoassay to measure B-type natriuretic peptide (BNP) (ADVIA Centaur XP; Siemens Healthcare Diagnostics, Inc., Tarrytown, NY, USA) Peripheral plasma samples were kept at $-80^{\circ} \mathrm{C}$ until retrieved for the measurement of the biomarkers (September 2011 for hsCRP and BNP, and February 2012 for IL-6). Investigators who performed the biomarker determination were blinded to the study participants' outcomes.

All-cause mortality since the date of study blood sampling was ascertained via manual and automated query of electronic medical records, as well as query of the Social Security Death Index. Lung transplantation was censored. The following data were collected on the same day as blood sampling: New York Heart Association (NYHA) functional classification, 6-min walking distance (6MWD), echocardiography, and per cent predicted diffusing capacity of the lung for carbon monoxide (DLCO \% pred). Right heart catheterisation data obtained closest to the date of study blood sampling were recorded (median time 27 days, interquartile range 5-66 days). Analyses were performed using JMP Pro 9.0.0 (SAS Institute Inc., Cary, NC, USA) and R version 2.14.2 (The R Project for Statistical Computing, http://www.r-project.org/). We used receiver operating characteristic (ROC) curve analysis, Kaplan-Meier curves and Cox models to determine the associations between biomarkers and mortality. We also used recursive partitioning treebased analysis, using the R function "rpart", to identify the group of biomarkers and baseline variables that had optimal discriminatory ability with regards to all-cause mortality. Each possible threshold of biomarker and baseline variable was evaluated to find the split that formed two groups with the greatest difference in 
survival (alive versus dead). Survival was measured by estimated event rates after exponential scaling, which accounts for the time each subject was followed. Within the patient subsets defined by the first split, the process was repeated to identify optimal splits at a second level. This repeated splitting was stopped when the goodness-of-fit of the tree model could no longer be improved with further splits, or when resulting subgroups fell to a size of $<20$ patients.

We enrolled 76 patients, 62 of whom were female, with a mean \pm SD of $51 \pm 14$ years. The types of $\mathrm{PAH}$ included 40 idiopathic, 10 heritable, 19 connective tissue disease-associated (13 scleroderma) and 7 congenital heart disease-associated. The cohort had a mean \pm SD $6 \mathrm{MWD}$ of $360 \pm 127 \mathrm{~m}$, pulmonary arterial pressure of $51 \pm 13 \mathrm{mmHg}$, right atrial pressure (RAP) of $10 \pm 6 \mathrm{mmHg}$, cardiac index $2.4 \pm 0.8 \mathrm{~L} \cdot \mathrm{min}^{-1} \cdot \mathrm{m}^{-2}$ and pulmonary vascular resistance of $11 \pm 7$ Wood units. 63 patients were on $\mathrm{PAH}$-targeted therapies, 32 of them were receiving parenteral prostacyclin.

The median (interquartile range) concentrations of the biomarkers were: IL-6 $3.82(1.79-9.87) \mathrm{pg} \cdot \mathrm{mL}^{-1}$, hsCRP $5.7(1.95-14.85) \mathrm{mg} \cdot \mathrm{L}^{-1}$ and BNP $59(19-132) \mathrm{pg} \cdot \mathrm{mL}^{-1}$. Plasma IL-6 correlated with the 6MWD $(\mathrm{r}=0.52, \mathrm{p}<0.0001)$ and RAP $(\mathrm{r}=0.26, \mathrm{p}=0.03)$. hsCRP correlated with the 6MWD $(\mathrm{r}=0.40, \mathrm{p}=0.001)$. During a median (interquartile range) follow-up of 2.8 (1.6-4.6) years, there were 22 deaths and five lung transplants. Both IL-6 and hsCRP were univariate predictors of mortality. On ROC curve analysis, IL-6 had better discriminant ability (IL-6 area under the curve 0.81 , hsCRP area under the curve 0.68 ). IL-6 concentrations $\geqslant 4.7 \mathrm{pg} \cdot \mathrm{mL}^{-1}$ had a sensitivity of $86 \%$ and a specificity of $72 \%$, and were associated with nine-fold increase in the risk of death (fig. 1a). A hsCRP level $\geqslant 7.5 \mathrm{mg} \cdot \mathrm{L}^{-1}$ was less strongly associated with mortality (hazard ratio (95\% CI) 4.80 (1.77-13.1), $\mathrm{p}<0.001$, sensitivity $77 \%$, specificity $67 \%$ ). Other univariate predictors of mortality included male sex, NYHA class, 6MWD, BNP, pericardial effusion, RAP and red cell distribution width. In a multivariable Cox model male sex, BNP and IL-6 were independently associated with mortality. When IL-6 was removed from the model, given its collinearity with hsCRP $(\mathrm{r}=0.71)$, then hsCRP entered the model. However, in the decision tree model only BNP, IL-6 and cardiac index were independent predictors.

In our cohort we confirmed that BNP levels above $180 \mathrm{pg} \cdot \mathrm{mL}^{-1}$, as previously reported $[5,6]$, were associated with an extremely poor prognosis, with 3-year survival of only $16 \%$ (hazard ratio (95\% CI) for death 13.01 (4.98-35.19), $\mathrm{p}<0.0001$ ). Thus, we were interested in the prognostic utility of IL-6 and hsCRP in patients with BNP levels below $180 \mathrm{pg} \cdot \mathrm{mL}^{-1}(\mathrm{n}=60)$. In this subpopulation, IL-6 levels $\geqslant 4.7 \mathrm{pg} \cdot \mathrm{mL}^{-1}$, RAP and DLCO \% pred were the only independent predictors of mortality in a forward stepwise Cox model

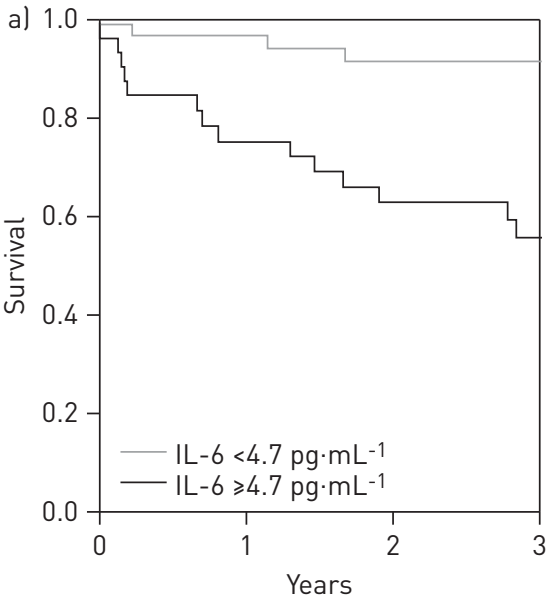

Number at risk

$\mathrm{IL}-6<4.7 \mathrm{pg} \cdot \mathrm{mL}^{-1} \quad 42$

$\mathrm{IL}-6 \geqslant 4.7 \mathrm{pg} \cdot \mathrm{mL}^{-1} \quad 34$
38

24
31

20

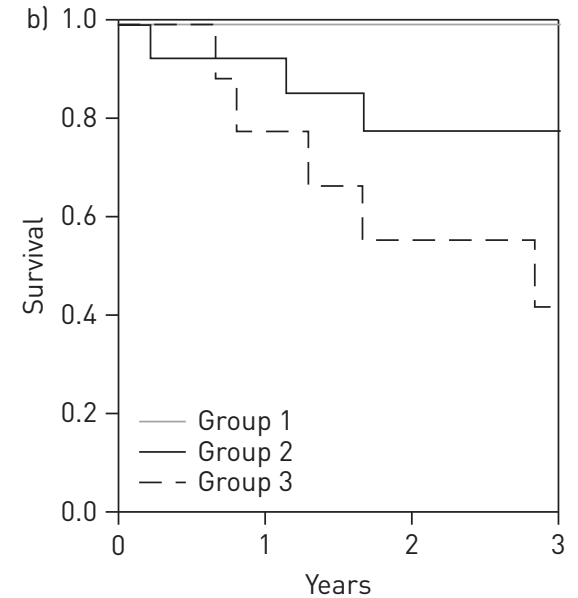

Number at risk

20

15

$\begin{array}{ll}\text { Group } 1 & 37 \\ \text { Group } 2 & 14 \\ \text { Group } 3 & 9\end{array}$

Group 39

$\begin{array}{cc}34 & 32 \\ 13 & 9 \\ 7 & 5\end{array}$

FIGURE 1 a) Transplant-free survival according to an interleukin (IL)-6 receiver operating characteristic curve identified cut-off of $4.7 \mathrm{pg} \cdot \mathrm{mL}^{-1}$. Hazard ratio $(95 \%$ CI) $9.26(2.74-31.3)$; $<<0.0001$. b) Transplant-free survival of 60 pulmonary arterial hypertension patients with B-type natriuretic peptide levels $<180 \mathrm{pg} \cdot \mathrm{mL}^{-1}$ according to recursive partitioning tree-based analysis identified groups. Group $1(\mathrm{n}=37): 6$-min walk distance $(6 \mathrm{MWD}) \geqslant 450 \mathrm{~m}$ or $6 \mathrm{MWD}<450 \mathrm{~m}$ and right atrial pressure (RAP) $<8 \mathrm{mmHg} ; 3$-year survival $100 \%$. Group $2(\mathrm{n}=14): 6 \mathrm{MWD}<450 \mathrm{~m}$ and $\mathrm{RAP} \geqslant 8 \mathrm{mmHg}$ and IL-6 $<5.6 \mathrm{pg} \cdot \mathrm{mL}^{-1}$; 3-year survival $78 \%$. Group $3(\mathrm{n}=9): 6 \mathrm{MWD}<450 \mathrm{~m}$ and RAP $\geqslant 8 \mathrm{mmHg}$ and IL-6 $\geqslant 5.6 \mathrm{pg} \cdot \mathrm{mL}^{-1} ; 3$-year survival $42 \%$. 
(all $\mathrm{p}<0.05$ ), while BNP was not. Recursive partitioning tree-based analysis showed that the combination of 6MWD (cut-off $450 \mathrm{~m}$ ), RAP (cut-off $8 \mathrm{mmHg}$ ) and IL-6 (cut-off $5.6 \mathrm{pg} \cdot \mathrm{mL}^{-1}$ ) offered the highest ability to separate groups of patients with significantly different survival. BNP was not found to provide any predictive information in this model either. Figure $1 \mathrm{~b}$ shows the survival curves for the tree-based analysis identified groups. The best prognosis was seen in patients with a good 6MWD or low RAP (group 1). Patients with more limited 6MWD and an elevated RAP, but with low plasma IL-6 levels had an intermediate prognosis (group 2). Those with limited 6MWD, high RAP and elevated plasma IL-6 had the worse outcome (group 3) (fig. 1b).

Plasma IL-6 levels were independent predictors of survival, both in a multivariable Cox proportional hazards model and in a recursive partitioning tree-based analysis. Importantly, plasma IL-6 level provided prognostic information, in conjunction with 6MWD and RAP, in patients with BNP levels below the established cut-off point of $180 \mathrm{pg} \cdot \mathrm{mL}^{-1}[5,6]$. It is very clear that patients with elevated BNP levels have a poor prognosis; however, our study shows that below the established threshold, BNP does not provide any prognostic information. In this subset of patients plasma IL-6, in conjunction with 6MWD and RAP, allows for further risk stratification. By contrast, hsCRP did not add independent information in PAH. As 69 patients had blood drawn more than 2 years prior to IL-6 measurement, uncertainty about stability of IL-6 is a limitation of this study. However, our data are consistent with previous findings on IL-6 [7-10]. Another limitation is the lack of a validation cohort and the modest sample size, which also prevented us from entering other biomarkers into the models.

In conclusion, plasma IL-6 provides incremental prognostic information in PAH, especially in patients with low BNP levels.

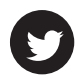

@ERSpublications

Plasma IL-6 provides prognostic information in pulmonary arterial hypertension, especially in patients with low BNP http://ow.ly/qzNkt

Gustavo A. Heresi ${ }^{1}$, Metin Aytekin ${ }^{2,3}$, Jeffrey P. Hammel ${ }^{1}$, Sihe Wang ${ }^{4}$, Soumya Chatterjee ${ }^{5}$ and Raed A. Dweik ${ }^{1}$

${ }^{1}$ Dept of Pulmonary and Critical Care Medicine, Respiratory Institute, Cleveland Clinic, Cleveland, OH, ${ }^{4}$ Dept of Clinical Pathology, Pathology and Laboratory Medicine Institute, Cleveland Clinic, Cleveland, OH, and ${ }^{5}$ Dept of Rheumatologic and Immunologic Disease, Orthopedic and Rheumatologic Institute; Cleveland Clinic, Cleveland, OH, USA. ${ }^{2}$ Dept of Medical Biology, Faculty of Medicine, Erciyes University, Kayseri, and ${ }^{3}$ Genome and Stem Cell Center, Erciyes University, Kayseri, Turkey.

Correspondence: R.A. Dweik, Dept of Pulmonary and Critical Care Medicine, Respiratory Institute, Cleveland Clinic, 9500 Euclid Avenue A90, Cleveland, OH 44195, USA. E-mail: dweikr@ccf.org

Received: Aug 022013 | Accepted after revision: Sept 302013 | First published online: Oct 172013

Conflict of interest: Disclosures can be found alongside the online version of this article at www.erj.ersjournals.com

\section{References}

Heresi GA. Clinical perspective: biomarkers in pulmonary arterial hypertension. Int J Clin Pract Suppl 2011; 169: 5-7. Steiner MK, Syrkina OL, Kolliputi N, et al. Interleukin-6 overexpression induces pulmonary hypertension. Circ Res 2009; 104: 236-244.

3 Genest J. C-reactive protein: risk factor, biomarker and/or therapeutic target? Can J Cardiol 2010; 26: Suppl. A, 41A-44A.

4 Galiè N, Hoeper MM, Humbert M, et al. Guidelines for the diagnosis and treatment of pulmonary hypertension: the Task Force for the Diagnosis and Treatment of Pulmonary Hypertension of the European Society of Cardiology (ESC) and the European Respiratory Society (ERS), endorsed by the International Society of Heart and Lung Transplantation (ISHLT). Eur Heart J 2009; 30: 2493-2537.

$5 \quad$ Nagaya N, Nishikimi T, Uematsu M, et al. Plasma brain natriuretic peptide as a prognostic indicator in patients with primary pulmonary hypertension. Circulation 2000; 102: 865-870.

6 Benza RL, Miller DP, Gomberg-Maitland M, et al. Predicting survival in pulmonary arterial hypertension: insights from the Registry to Evaluate Early and Long-Term Pulmonary Arterial Hypertension Disease Management (REVEAL). Circulation 2010; 122: 164-172.

7 Soon E, Holmes AM, Treacy CM, et al. Elevated levels of inflammatory cytokines predict survival in idiopathic and familial pulmonary arterial hypertension. Circulation 2010; 122: 920-927.

8 Selimovic N, Bergh $\mathrm{CH}$, Andersson B, et al. Growth factors and interleukin-6 across the lung circulation in pulmonary hypertension. Eur Respir J 2009; 34: 662-668.

9 Rhodes CJ, Wharton J, Howard LS, et al. Red cell distribution width outperforms other potential circulating biomarkers in predicting survival in idiopathic pulmonary arterial hypertension. Heart 2011; 97: 1054-1060.

10 Humbert M, Monti G, Brenot F, et al. Increased interleukin-1 and interleukin-6 serum concentrations in severe primary pulmonary hypertension. Am J Respir Crit Care Med 1995; 151: 1628-1631. 